\title{
Involvement of Sphingosine 1-Phosphate in Palmitate-Induced Non-Alcoholic Fatty Liver Disease
}

\author{
Frdoos Al Fadel Susann Fayyaz Lukasz Japtok Burkhard Kleuser \\ Faculty of Mathematics and Natural Science, Institute of Nutritional Science, Department of Toxicology, \\ University of Potsdam, Potsdam, Germany
}

\section{Key Words}

Palmitate - Liver fibrosis $\cdot$ Sphingosine 1-phosphate $\cdot$ Hepatic stellate cells $\bullet$ Hepatocytes $\bullet$ $\alpha-S M A$

\begin{abstract}
Background/Aims: Ectopic lipid accumulation in hepatocytes has been identified as a risk factor for the progression of liver fibrosis and is strongly associated with obesity. In particular, the saturated fatty acid palmitate is involved in initiation of liver fibrosis via formation of secondary metabolites by hepatocytes that in turn activate hepatic stellate cells (HSCs) in a paracrine manner. Methods: $\alpha$-smooth muscle actin-expression ( $\alpha$-SMA) as a marker of liver fibrosis was investigated via western blot analysis and immunofluorescence microscopy in HSCs (LX-2). Sphingolipid metabolism and the generation of the bioactive secondary metabolite sphingosine 1-phosphate (S1P) in response to palmitate were analyzed by LCMS/MS in hepatocytes (HepG2). To identify the molecular mechanism involved in the progression of liver fibrosis real-time PCR analysis and pharmacological modulation of S1P receptors were performed. Results: Palmitate oversupply increased intra- and extracellular S1P-concentrations in hepatocytes. Conditioned medium from HepG2 cells initiated fibrosis by enhancing $\alpha$-SMA-expression in LX-2 in a S1P-dependent manner. In accordance, fibrotic response in the presence of S1P was also observed in HSCs. Pharmacological inhibition of $\mathrm{S} 1 \mathrm{P}$ receptors demonstrated that $\mathrm{S}_{1} \mathrm{P}_{3}$ is the crucial receptor subtype involved in this process. Conclusion: S1P is synthesized in hepatocytes in response to palmitate and released into the extracellular environment leading to an activation of $\mathrm{HSCs}$ via the $\mathrm{S1P}_{3}$ receptor.

\section{Introduction}

Non-alcoholic fatty liver disease (NAFLD) has been identified as a risk factor for progression of liver fibrosis and is strongly associated with insulin resistance and obesity [1]. Excess lipid accumulation in liver results in oxidative stress, mitochondrial dysfunction, production of pro inflammatory cytokines and apoptosis [2,3]. These negative effects are


mainly induced by saturated fatty acids (SFA) especially palmitate that is enhanced in obese individuals [4]. In contrast, mono- and poly-unsaturated fatty acids have been discussed to possess a protective effect on hepatocytes via accumulation of triacylglycerols (TAGs) in lipid droplets [5]. The lipotoxic effect of SFAs is a central contributor to the progression of liver fibrosis but the molecular mechanism is not fully understood. Hepatic stellate cells (HCSs) are main mediators of this fibrogenic process. Activation of HSCs leads to cellular changes like transdifferentiation into myofibroblastic HSCs and is accompanied by production of extracellular matrix proteins (ECM) and collagen [6-8]. The increased expression of ECM like $\alpha$-smooth muscle actin ( $\alpha$-SMA) enhances cell contractility and is considered as a pivotal event of hepatic fibrosis. Various intracellular signal transduction pathways are involved in activation of HSCs and hepatic fibrosis $[9,10]$. Previously, it has been shown that ceramides are formed from palmitate in hepatocytes by de novo sphingolipid synthesis and play an important role in pathogenesis of liver fibrosis [11, 12]. Moreover, it has been proposed that released meditators from hepatocytes during a lipid oversupply may contribute to the activation of HSCs [13]. Once generated, ceramides can be further metabolized to the bioactive metabolite sphingosine 1-phosphate (S1P). S1P can be released via specific ATPbinding cassette $(\mathrm{ABC})$-transporters or via the S1P transporter spinster homolog 2 into the extracellular environment and activates 5 specific G protein-coupled S1P receptors $\left(\mathrm{S}_{1} \mathrm{P}_{1-5}\right)$ in an auto- and paracrine manner $[14,15]$. In addition to well established effects of S1P in pathogenesis of metabolic diseases, a growing body of evidence indicates that S1P can be considered as an important regulator of fibrosis $[16,17]$. S1P exhibits pro- as well as antifibrotic activities depending on the site of action. Intracellular formed S1P possesses anti fibrotic effects, whereas extracellular S1P provokes fibrosis in a S1P receptor-dependent manner [18].

The main aim of this study was to investigate the interaction between ectopic lipid accumulation in hepatocytes and HSCs activation. As a model for hepatic steatosis, hepatocytes were incubated with palmitate and the conditioned media (CM) was used to initiate HSC activation. Palmitate induced the formation of intracellular S1P in hepatocytes that was released into the extracellular environment. Moreover, S1P was identified to mediate a fibrotic response in $\mathrm{HSC}$ via stimulation of the $\mathrm{S}_{1} \mathrm{P}_{3}$ receptor subtype. Most interestingly, $\mathrm{CM}$ lost its ability to activate HSC in the presence of a $\mathrm{S}_{1} \mathrm{P}_{3}$ antagonist suggesting a novel therapeutic target for the treatment of liver fibrosis.

\section{Materials and Methods}

\section{Materials}

S1P was obtained from Biomol (Hamburg, Germany). D7-S1P was from Avanti Polar Lipids (Alabaster, USA). D-MEM (Dulbecco`s modified Eagle`s medium) and BSA (bovine serum albumin) were ordered from Biochrom (Berlin, Germany), JTE-013 was from Cayman (Hamburg, Germany). SEW2871 was obtained from Merck Biosciences (Darmstadt, Germany). VPC24191 and VPC23019 were purchased from Avanti Polar Lipids (Alabaster, USA). Polyvinylidene difluoride (PVDF) membranes were received from Millipore (Schwalbach, Germany). Monoclonal rabbit, secondary anti-rabbit IgG horseradish peroxidase (HRP)linked antibody as well as LumiGLO reagent and peroxide chemiluminescent substrate were provide by Cell Signaling Technology (Frankfurt, Germany). Alexa 488 green-conjugated goat anti-rabbit IgG was from Thermo Scientific (Dreieich, Germany). Primers were synthesized by EurofinsMWG Operon (Ebersberg, Germany). All other chemicals were purchased from Sigma-Aldrich (Schnelldorf, Germany). Rabbit monoclonal anti- $\alpha$-smooth muscle actin ( $\alpha$-SMA) antibodies and monoclonal anti- $\beta$-actin antibody were received from Abcam (Cambridge, UK).

\section{Cell culture}

LX-2 cells, an immortalized human HSC line, were provided by SL Friedman (Mount Sinai School of Medicine, New York, NY). HepG2 and LX-2 cells were cultured in DMEM containing 10\% FBS, antibiotics (100 U/ml penicillin and $100 \mu \mathrm{g} / \mathrm{ml}$ streptomycin). The cells were grown at $37^{\circ} \mathrm{C}$ in an incubator with $5 \%$ $\mathrm{CO}_{2}$.

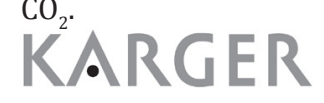




\section{Cellular Physiology Cell Physiol Biochem 2016;40:1637-1645 \\ \begin{tabular}{l|l} 
and Biochemistry 10.1159/000453213 & $\begin{array}{l}\text { (C) 2016 The Author(s). Published by S. Karger AG, Basel } \\
\text { www.karger.com/cpb }\end{array}$
\end{tabular}}

Al Fadel et al.: Sphingosine 1-Phosphate and Liver Fibrosis

Sphingolipid quantification

S1P was extracted and quantified as recently described [11]. Briefly, lipid extraction was performed using D7-S1P as internal standard. Sample analysis was carried out by rapid-resolution liquid chromatographyMS/MS using a QQQ 6490 mass spectrometer (Agilent Technologies, Waldbronn, Germany) operating in the positive ESI mode. The precursor ions of S1P (m/z 380.3) and D7-S1P $(\mathrm{m} / \mathrm{z} 387.3)$ were cleaved into the fragment ions of $\mathrm{m} / \mathrm{z} 264.3$ and $\mathrm{m} / \mathrm{z} 271.3$ respectively. Ceramides were extracted and quantified as recently described [14]. Briefly, lipid extraction was performed using C17-ceramide as internal standard. Sample analysis was carried out by rapid-resolution liquid chromatography-MS/MS using a Q-TOF 6530 mass spectrometer (Agilent Technologies, Waldbronn, Germany) operating in the positive ESI mode. The precursor ions of ceramides (C16-ceramide (m/z 520.508), C17-ceramide (m/z 534.524), C18-ceramide ( $\mathrm{m} / \mathrm{z}$ 548.540), C20-ceramide ( $\mathrm{m} / \mathrm{z}$ 576.571), C22-ceramide ( $\mathrm{m} / \mathrm{z}$ 604.602), C24-ceramide ( $\mathrm{m} / \mathrm{z}$ 632.634), C24:1-ceramide (m/z 630.618)) were cleaved into the fragment ion of $\mathrm{m} / \mathrm{z} 264.270$. Quantification was performed with Mass Hunter Software (Agilent Technologies).

Real-time PCR

Total RNA was extracted as recommended by the manufacturer using the Universal RNA Purification Kit (Roboklon, Berlin, Germany), then total RNA ( $2 \mu \mathrm{g}$ ) was reversely transcribed using the Revert Aid firststrand cDNA synthesis kit (Fermentas, St Leon-Rot, Germany). An amount of $50 \mathrm{ng}$ cDNA was subjected to amplification by quantitative real-time PCR using a Light Cycler 480 and the SYBR-Green master mix under the following incubation conditions: $95^{\circ} \mathrm{C}$ for $5 \mathrm{~min}, 45$ cycles of $95^{\circ} \mathrm{C}$ for $10 \mathrm{~s}, 58^{\circ} \mathrm{C}$ for $10 \mathrm{~s}$, and $72^{\circ} \mathrm{C}$ for $10 \mathrm{~s}$, followed by $72^{\circ} \mathrm{C}$ for $5 \mathrm{~min}$ and cooled to $4^{\circ} \mathrm{C}$. $\beta$-actin was used as normalization control. Huaman Oligonucleotide primers $\left(5^{\prime} \rightarrow 3^{\prime}\right)$ were as follows: S1PR: GCC CAT GGC CAA CTC ACT TCTGA (forward), GCT GAC AGG GCC ACA AAC ATAC (reverse); S1PR : GCT GGC CAC TTG ACG ACT TCTCC (forward), GCT TCT CTC TGC CTT GCT CAG (reverse); S1PR $_{3}$ : CAA TAG CAG CCA TCT CCG AAGGT (forward), GGC AGG CTG TTG GTC AAA GTA AGG (reverse); S1PR 4 : TCC TCA ACT CGG CGG TCAAC (forward), GGC AGG CTG TTG GTC AAA GTA AGG (reverse); S1PR 5 : GCC ATG GCC AAC TCA CTT CTGA (forward), CAC CTT TGG CTG CAT TTC CTACA (reverse); $\beta$-actin: CCC CAA GGC CAA CCG CGA GAA GATG (forward), AGG TCC CGG CCA GCC AGG TCCAG (reverse).

\section{Immunoblotting}

$\alpha$-SMA was detected by Western blotting as follows. Whole cell lysates were resolved by $10 \%$ SDSpolyacrylamide gel electrophoresis. The proteins were transferred into PVDF membrane and blocked with non-fat dry milk in Tris-buffered saline/Tween 20 (TBS-T) and incubated with 1:400 dilution of anti- $\alpha$-SMA antibody in TBS-T overnight at $4^{\circ} \mathrm{C}$. The blots were washed and incubated with 1:1000 anti-rabbit HRPlinked secondary antibodies for $1 \mathrm{~h}$ at room temperature. The blots were repeatedly washed and incubated in detection reagent LumiGLO according to the manufacturer's protocol using a ChemiDoc XRS+ system (Bio-Rad Laboratories, Munich, Germany).

\section{Immunofluorescence Microscopy of $\alpha$-SMA}

LX-2 cells were seeded into 6-well plates, each containing a glass coverslip, and cultured for $24 \mathrm{~h}$ in DMEM containing $10 \%$ FBS, and antibiotics $(100 \mathrm{U} / \mathrm{ml}$ penicillin and $100 \mu \mathrm{g} / \mathrm{ml}$ streptomycin).Then they were serum-deprived for $18 \mathrm{~h}$ in DMEM supplemented with $100 \mathrm{U} / \mathrm{ml}$ penicillin and $100 \mu \mathrm{g} / \mathrm{ml}$ streptomycin. LX-2 cells were stimulated with S1P for $4 \mathrm{~h}$. Cells were washed with ice-cold PBS and fixed in $2 \%$ paraformaldehyde and permeabilized in $0.5 \%$ Triton X-100 at room temperature for $15 \mathrm{~min}$. Cells were blocked with $5 \%$ BSA for 60 min followed by incubation with anti- $\alpha$-SMA antibodies 1:200 overnight at $4^{\circ} \mathrm{C}$. After that, incubation with Goat anti-rabbit Alexa 488 1:1000 was performed for $2 \mathrm{~h}$. The samples were covered with mounting medium containing DAPI and viewed with a fluorescence microscope Nikon Eclipse E 1000 microscope with a 20x magnification and analyzed with a computer-assessed histomorphometry program (Lucia G 4.82; Nikon, Düsseldorf, Germany).

\section{Statistical analyses}

Data are expressed as the mean \pm SEM of results of three independent experiments. Statistical analyses ( $t$ tests) were performed using GraphPad Prism 6.0 software (GraphPad Software, La Jolla, CA, US). Values of ${ }^{*} p<0.05$ and ${ }^{* *} p<0.01$ indicate a statistically significant difference vs control experiments. 


\section{Results}

CM from palmitate-treated hepatocytes provokes pro-fibrotic response in HSCs

To investigate the role of secondary metabolites that are generated in response to palmitate, HepG2 cells were cultivated in the presence of this SFA. Then HSCs (LX-2 cells) were treated with CM from palmitate-treated HepG2 cells, and $\alpha$-SMA expression was measured via western blot as a marker of HSCs activation. As presented in Fig. 1A, a significant increase of $\alpha$-SMA levels could be detected after $2 \mathrm{~h}$ treatment with CM obtained from palmitate-treated hepatocytes. To further examine that the fibrotic effect of CM was not due to palmitate residues in the CM, LX-2 cells were stimulated with palmitate $(0.3 \mathrm{mmol} / \mathrm{L})$. As presented in Fig. 1B, palmitate had no significant effect on $\alpha$-SMA expression in HSCs.

\section{Role of sphingolipids in palmitate-mediated HSC activation}

Sphingolipid metabolism can be modulated by palmitate as it acts as a direct substrate for the de novo sphingolipid synthesis. Therefore, sphingolipid metabolism, in particular generation of S1P and ceramides in response to palmitate was measured in hepatocytes. LC-MS/MS analysis revealed a significant increase in both intra- and extracellular S1P-levels in HepG2 cells. There was a 1.5-fold elevation of intracellular S1P-levels (Fig. 2A), whereas the extracellular content of S1P increased almost 2-fold (Fig. 2B). Interestingly, palmitate exposure also induced a significant increase of intracellular ceramide levels in HepG2 but no ceramides could be detected in the extracellular environment (data not shown). These data indicate that palmitate stimulates the formation of sphingolipid species such as ceramides and S1P, but only the intracellular synthesized S1P is released into the extracellular environment.

\section{S1P induces fibrotic HSC activity}

In order to investigate the fibrotic effect of S1P, LX-2 cells were treated with different S1P concentrations for indicated time periods and the expression of $\alpha$-SMA was analyzed

Fig. 1. Activation of LX-2 cells by CM from palmitate treated HepG2. LX-2 cells were incubated for $4 \mathrm{~h}$ in the presence of CM from HepG2 cells being treated with vehicle or $0.3 \mathrm{mmol} / \mathrm{L}$ palmitate for the indicated time periods (A). LX-2 cells were directly treated with vehicle or $0.3 \mathrm{mmol} / \mathrm{L}$ palmitate for $4 \mathrm{~h}(\mathrm{~B})$. $\alpha$-SMA was measured by western blot analysis and quantified by densitometric normalization to $\beta$-actin levels. Data are expressed as the mean \pm SEM of the results from three independent experiments. ${ }^{*} p<$ 0.05 and ${ }^{* *} p<0.01$ indicate a statistically significant difference vs experiments with vehicle stimulation.

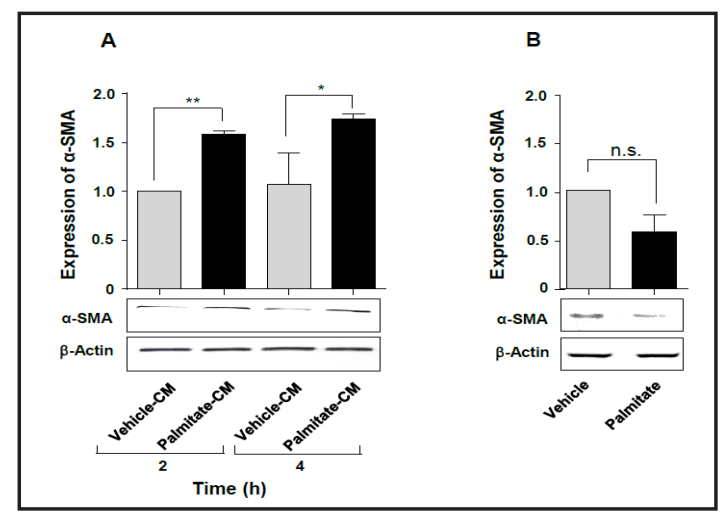

Fig. 2. Formation of S1P in response to palmitate in HepG2 cells. HepG2 cells were cultured as described in methods. After $18 \mathrm{~h}$ of culture, the cells were treated with vehicle (gray bars) or with $0.3 \mathrm{mmol} / \mathrm{L}$ palmitate (black bars) for $2 \mathrm{~h}$. S1P-levels were determined in HepG2 cells (intracellular) (A) and in CM (extracellular) (B) by LC-MS/MS analysis. Data are expressed as the mean \pm SEM of the results from three independent experiments. $* p<0.05$ indicates a statistically significant difference vs experiments with vehicle stimulation.

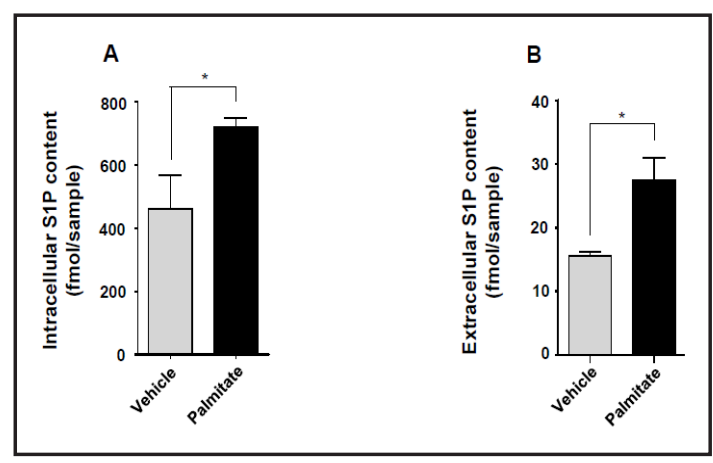




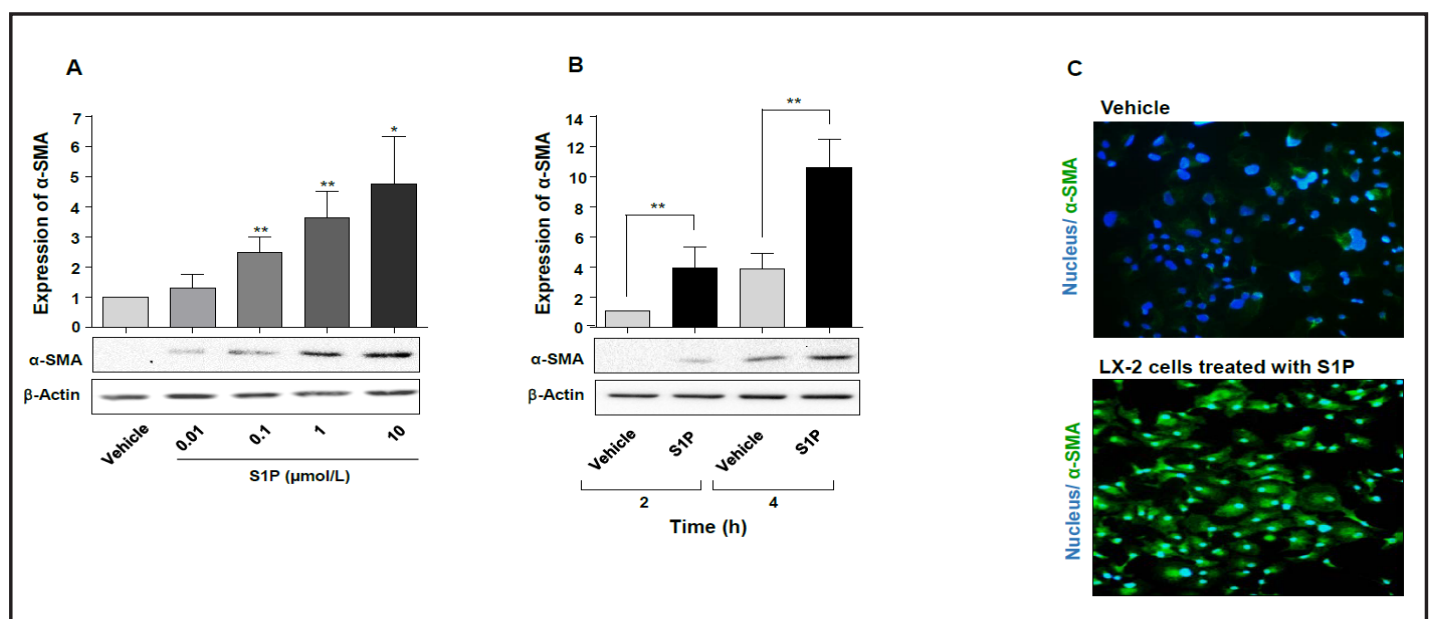

Fig. 3. Induction of $\alpha$-SMA production in LX-2 cells in response to S1P. Cells were treated with indicated concentrations of S1P for $2 \mathrm{~h}(\mathrm{~A})$ or $1 \mu \mathrm{mol} / \mathrm{L} \mathrm{S1P}$ for the indicated time periods (B). $\alpha$-SMA was measured by western blot analysis and quantified by densitometric normalization to $\beta$-actin levels. Data are expressed as the mean \pm SEM of the results from three independent experiments. ${ }^{*} p<0.05$ and ${ }^{* *} p<0.01$ indicate a statistically significant difference vs experiments with vehicle stimulation. (C) LX-2 cells were stimulated with $\mathrm{S} 1 \mathrm{P}(1 \mu \mathrm{mol} / \mathrm{L})$ for $4 \mathrm{~h}$ followed by an immunofluorescence analysis of $\alpha$-SMA (original magnification X 20).

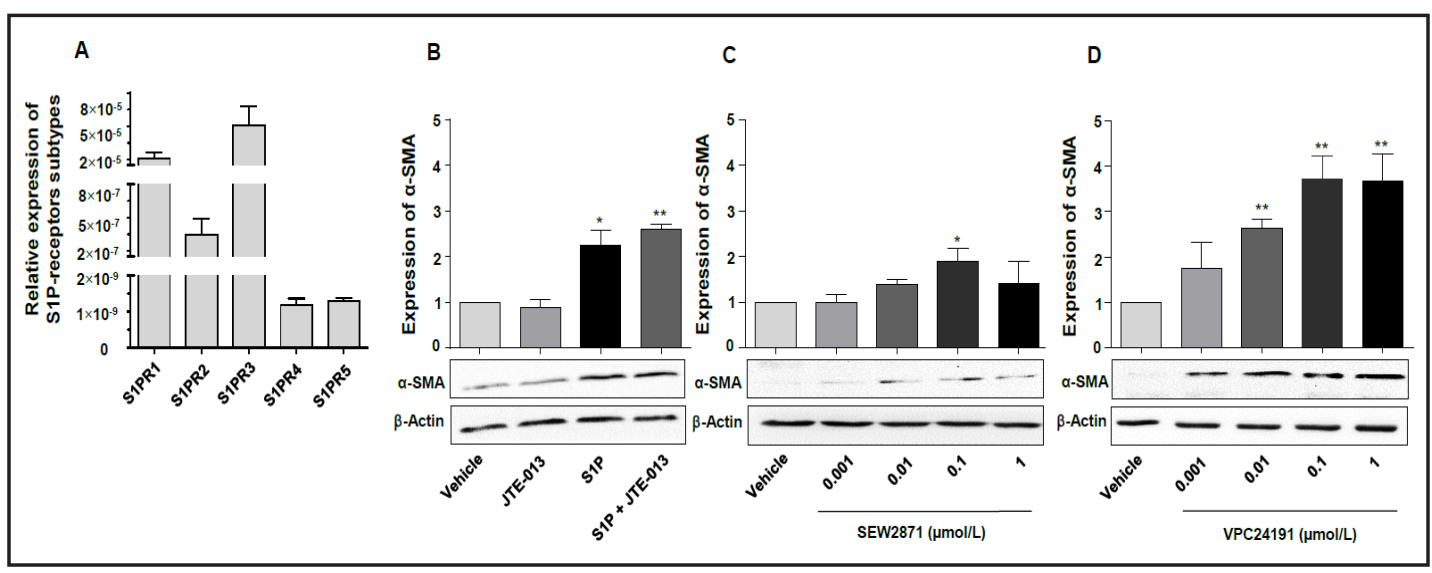

Fig. 4. Involvement of S1P receptors in S1P-mediated LX-2 cells activation. Real-time PCR was performed as described in materials and methods. The relative amount of detectable S1P receptors subtypes were $\mathrm{S}_{3} \mathrm{P}_{3}>$

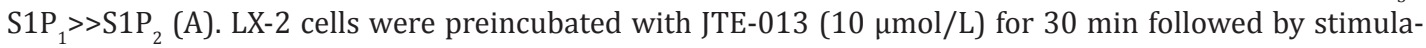
tion with S1P (1 $\mu \mathrm{mol} / \mathrm{L})$ for $4 \mathrm{~h}(\mathrm{~B})$. LX-2 cells were stimulated for $4 \mathrm{~h}$ with the indicated concentrations of SEW2871 (C) and VPC24191 (D). $\alpha$-SMA was measured by Western blot analysis and quantified by densitometric normalization to $\beta$-actin levels. Data are expressed as the mean \pm SEM of the results from three independent experiments. ${ }^{*} p<0.05$ and ${ }^{* *} p<0.01$ indicate a statistically significant difference vs experiments with vehicle stimulation.

by western blot and immunofluorescence microscopy. S1P stimulation induced a significant activation of $\alpha$-SMA expression in HSC in a dose-dependent manner (Fig. 3A). Furthermore, a significant increase of $\alpha$-SMA was already visible after $2 \mathrm{~h}$ and reached a maximum after 4 h S1P stimulation (Fig. 3B). In agreement with western blot analysis, immunofluorescence detection showed also an increase in $\alpha$-SMA expression in response to S1P (Fig. 3C). 
Fig. 5. Participation of $\mathrm{S}_{1} \mathrm{P}_{1 / 3}$ in palmitate-mediated activation of LX-2 cells. LX-2 cells were preincubated with $1 \mu \mathrm{mol} / \mathrm{L}$ VPC23019 for $30 \mathrm{~min}$ followed by incubation for $4 \mathrm{~h}$ with the CMs from HepG2 being treated with vehicle or $0.3 \mathrm{mmol} / \mathrm{L}$ palmitate for $2 \mathrm{~h}$. Data are expressed as the mean \pm SEM of the results from three independent experiments. ${ }^{*} p<0.05$ and ${ }^{* *} p<0.01$ indicate a statistically significant difference vs experiments with vehicle stimulation.

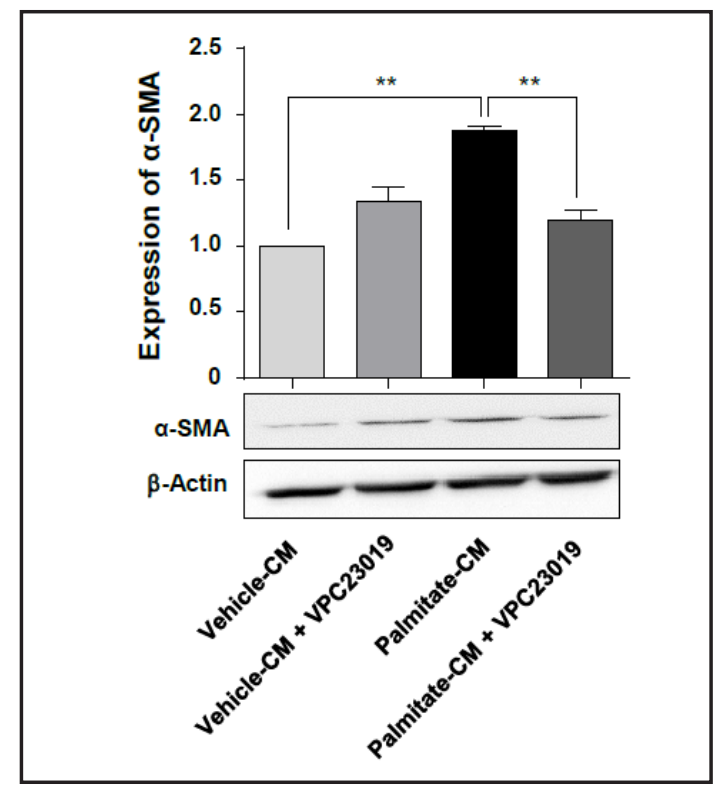

S1P induces LX-2 activation via $S 1 P_{1 / 3}$ receptor subtypes

Expression of S1P receptor subtypes was determined in LX-2 indicating that all five $\mathrm{S} 1 \mathrm{P}$ receptors are present with a dominant expression of $\mathrm{S}_{1} \mathrm{P}_{1}$ and $\mathrm{S}_{1} \mathrm{P}_{3}$ (Fig. 4A). To further investigate the role of S1P receptors in LX-2 activation, S1P receptors were modulated by different pharmacological approaches. Pretreatment of HSCs with JTE-013 (10 $\mu \mathrm{mol} / \mathrm{L})$, a specific $\mathrm{S}_{2} \mathrm{P}_{2}$ receptor antagonist had no effect on S1P-induced HSC activation (Fig. 4B). As presented in Fig.4C, SEW2871, a S1P ${ }_{1}$ receptor agonist only slightly increased $\alpha$-SMA expression. Moreover, a pronounced increase in $\alpha$-SMA was detected after treatment of LX-2 with VPC24191, a specific $\mathrm{S}_{1} \mathrm{P}_{1 / 3}$ receptor agonist, indicating that mainly the $\mathrm{S}_{1} \mathrm{P}_{3}$ receptor subtype is responsible for HSC activation (Fig. 4D).

The role of $S 1 P$ in palmitate-mediated $L X-2$ activation via $S 1 P_{3}$ receptor subtypes

Next, it was of interest to examine, whether hepatocyte-derived S1P is involved in LX-2 activation. Therefore, LX-2 were stimulated with $\mathrm{CM}$ in the presence of the competitive $\mathrm{S}_{1} \mathrm{P}_{1 / 3}$ antagonist VPC23019. Most interestingly, CM-mediated $\alpha$-SMA expression was significantly reduced in the presence of VPC23019 (Fig. 5). These data provide evidence that the palmitate-induced formation of S1P in hepatocytes and its release into the extracellular environment contributes to an activation of HSCs.

\section{Discussion}

NAFLD is normally associated with hepatic steatosis and an increased lipid accumulation in hepatocytes [1]. This metabolic disorder is a risk factor for the progression of liver fibrosis and is strongly accompanied by insulin resistance and obesity. HSCs are main mediators for the initiation of liver fibrosis. The activation of HSCs leads to their transdifferentiation into myofibroblastic HSCs leading to phenotypic transformation, the production of ECM, collagen $[7,8]$ and an increased expression of $\alpha$-SMA [9].

One main source of hepatic lipids are SFAs, in particular palmitate, which are elevated in serum of obese individuals [19]. Excess accumulation of SFAs results in oxidative stress, mitochondrial dysfunction, production of pro inflammatory cytokines and apoptosis of hepatocytes [20]. The underlying molecular mechanisms responsible for the interaction between hepatic steatosis and liver fibrosis are not fully understood [9]. Previously, it was 
shown by Wobser et al. that palmitate is involved in the initiation of liver fibrosis through secondary metabolites that activate HSCs [13]. This is in agreement with our work showing an activation of HSCs after stimulation with CM of palmitate-stimulated hepatocytes while direct palmitate exposure of HSCs had no fibrotic effect. These results indicate that palmitate-derived metabolites are responsible for the fibrotic response. It is well known that palmitate can be used as a substrate for the de novo synthesis of sphingolipids. Several lines of evidence support a role for these sphingolipid derivatives especially ceramides in the pathogenesis of hepatic fibrosis [12]. Interestingly, our study indicates an enhanced ceramide accumulation in hepatocytes in response to palmitate but no release of this sphingolipid into the CM. Nevertheless, ceramides can be further metabolized to S1P, which is a bioactive lipid mediator that is involved in numerous signaling pathways and regulates a wide variety of cellular functions [21]. Several studies indicate an increase of S1P in response to palmitate in different cell types such as myotubes and pancreatic $\beta$-cells either via activation of sphingosine kinase or de novo synthesis $[22,23]$. S1P exhibits pro- as well as anti-fibrotic activities depending on the site of action. Intracellular formed S1P possesses anti fibrotic effects, whereas extracellular S1P provokes fibrosis in a S1P receptor dependent manner [18]. Indeed, this study clearly provides evidence that hepatic S1P formation is significantly increased after palmitate exposure in HepG2 cells. In contrast to ceramide formation, increased levels of S1P can not only be detected within the cells but also in the extracellular environment. This is in accordance with the fact that S1P can be actively transported by ABC transporters, namely ABCC1 and ABCG2 [24] or via the S1P transporter spinster homolog 2 [25]. Most recently it has been indicated that mRNA of this transporter is increased in human liver with advanced fibrosis [25]. This is in conclusion with a variety of studies demonstrating that hepatic S1P formation is significantly increased in human fibrotic liver and S1P exerts a powerful migratory effect on hepatic myofibroblasts and in the progression of fibrosis in animal models $[4,26]$. In accordance, our results demonstrate that $\mathrm{S} 1 \mathrm{P}$ is able to activate HSCs as it induces a pronounced $\alpha$-SMA expression. Due to the fact that extracellular effects of S1P are carried out by binding and activation of S1P receptors, it was of interest to identify the receptor subtype responsible for the fibrotic action. This study indicates a reduced fibrotic property of $\mathrm{CM}$ from palmitate-treated hepatocytes in the presence of the

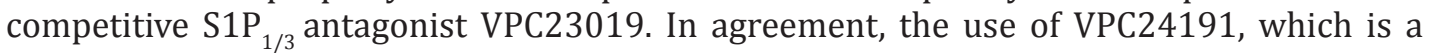

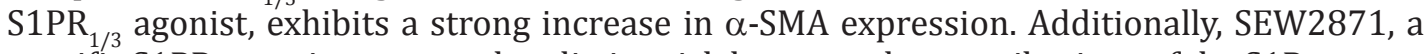
specific S1PR $\mathrm{P}_{1}$ agonist, was used to distinguish between the contributions of the $\mathrm{S}_{1} \mathrm{P}_{1}$ versus $\mathrm{S} \mathrm{P}_{3}$ on liver fibrosis. $\mathrm{S}_{1} \mathrm{P}_{1}$ activation can only partly induce $\alpha$-SMA expression revealing the more important role of $\mathrm{S}_{1} \mathrm{P}_{3}$ in HSCs activation. Measurement of the receptor profile in HSCs indicated a predominant expression of the $\mathrm{S}_{1} \mathrm{P}_{3}$ receptor subtype, confirming the crucial role of this receptor subtype on HSCs activation. In agreement with our findings, the role of $\mathrm{S}_{1} \mathrm{P}_{1 / 3}$ for the migratory response and the fibrogenic activation of HSCs have been clearly indicated in a variety of studies. Furthermore, the involvement of the $\mathrm{S} 1 \mathrm{P} / \mathrm{S} 1 \mathrm{P}_{3}$ receptor axis in vivo has been suggested in several fibrotic models $[27,28]$. On the contrary, it has been shown that the ${\mathrm{S} 1 \mathrm{P}_{2}}_{2}$ receptor subtype also contributes to a fibrotic response. In $\mathrm{S}_{1} \mathrm{P}_{2}$-knockout mice, application of dimethylnitrosamine as trigger factor for acute liver injury resulted in an enhanced regenerative response and injury protection when compared to wildtype mice [26]. Nevertheless, our data indicate that inhibition of the $\mathrm{S}_{1} \mathrm{P}_{2}$ receptor does not influence the fibrotic response of S1P.

The main aim of this study was to understand the molecular mechanisms responsible for the progression of NAFLD from steatosis to fibrosis. Taken together, the SFA palmitate, which is elevated in obesity and steatotic liver, can be utilized as a substrate for the de novo sphingolipid metabolism and induces an elevation of intra and extracellular S1P-levels in hepatocytes. This bioactive lipid may act on HSCs in a paracrine mechanism via binding to $\mathrm{S}_{1} \mathrm{P}_{3}$ to evoke their activation. In particular, these findings indicate that $\mathrm{S} \mathrm{P}_{3}$ inhibitions can be considered as a potential therapeutic target for liver fibrosis. 


\begin{tabular}{|c|c|c|}
\hline $\mathrm{Ce}$ & Cell Physiol Biochem 2016;4C & 0:1637-1645 \\
\hline and Biochemistry & $\begin{array}{l}\text { DOI: } 10.1159 / 000453213 \\
\text { Published online: December 23, } 2016\end{array}$ & $\begin{array}{l}\text { O } 2016 \text { The Author(s). Published by S. Karger AG, Basel } \\
\text { www.karger.com/cpb }\end{array}$ \\
\hline
\end{tabular}

\section{Abbreviation}

ABC (ATP-binding cassette); $\alpha$-SMA ( $\alpha$-smooth muscle actin); BSA (Bovine serum albumin); CM (Conditioned medium); ECM (Extracellular matrix); FBS (Fetal bovine serum); GPCR (G protein-coupled receptor); HSCs (Hepatic stellate cells), HRP (Horseradish peroxidase); NAFLD (Non-alcoholic fatty liver disease); S1P (Sphingosine 1-phosphate); SFA (saturated fatty acid); TAG (Triacylglycerol).

\section{Disclosure Statement}

The authors declare no competing or financial interests.

\section{References}

1 Akbar DH, Kawther AH: Non-alcoholic fatty liver disease and metabolic syndrome: what we know and what we don't know. Med Sci Monit 2006;12:RA23-26.

2 Fujii H, Kawada N: Inflammation and fibrogenesis in steatohepatitis. J Gastroenterol 2012;47:215-225.

3 Perez-Carreras M, Del Hoyo P, Martin MA, Rubio JC, Martin A, Castellano G, Colina F, Arenas J, Solis-Herruzo JA: Defective hepatic mitochondrial respiratory chain in patients with nonalcoholic steatohepatitis. Hepatology 2003;38:999-1007.

4 Boden G: Obesity, insulin resistance and free fatty acids. Curr Opin Endocrinol Diabetes Obes 2011;18:139143.

5 Mei S, Ni HM, Manley S, Bockus A, Kassel KM, Luyendyk JP, Copple BL, Ding WX: Differential roles of unsaturated and saturated fatty acids on autophagy and apoptosis in hepatocytes. J Pharmacol Exp Ther 2011;339:487-498.

6 Lee YA, Wallace MC, Friedman SL: Pathobiology of liver fibrosis: a translational success story. Gut 2015;64:830-841.

7 Bataller R, Brenner DA: Hepatic stellate cells as a target for the treatment of liver fibrosis. Semin Liver Dis 2001;21:437-451.

8 Eng FJ, Friedman SL: Fibrogenesis I. New insights into hepatic stellate cell activation: the simple becomes complex. Am J Physiol Gastrointest Liver Physiol 2000;279:G7-G11.

9 Crespo Yanguas S, Cogliati B, Willebrords J, Maes M, Colle I, van den Bossche B, de Oliveira CP, Andraus W, Alves VA, Leclercq I, Vinken M: Experimental models of liver fibrosis. Arch Toxicol 2016;90:1025-1048.

10 Pinzani M, Marra F: Cytokine receptors and signaling in hepatic stellate cells. Semin Liver Dis 2001;21:397416.

11 Fayyaz S, Henkel J, Japtok L, Kramer S, Damm G, Seehofer D, Puschel GP, Kleuser B: Involvement of sphingosine 1-phosphate in palmitate-induced insulin resistance of hepatocytes via the S1P2 receptor subtype. Diabetologia 2014;57:373-382.

12 Li JF, Qu F, Zheng SJ, Ren F, Wu HL, Liu M, Ren JY, Chen Y, Duan ZP, Zhang JL: Plasma sphingolipids: potential biomarkers for severe hepatic fibrosis in chronic hepatitis C. Mol Med Rep 2015;12:323-330.

13 Wobser H, Dorn C, Weiss TS, Amann T, Bollheimer C, Buttner R, Scholmerich J, Hellerbrand C: Lipid accumulation in hepatocytes induces fibrogenic activation of hepatic stellate cells. Cell Res 2009;19:9961005.

14 Fayyaz S, Japtok L, Kleuser B: Divergent role of sphingosine 1-phosphate on insulin resistance. Cell Physiol Biochem 2014;34:134-147.

15 Thuy AV, Reimann CM, Hemdan NY, Graler MH: Sphingosine 1-phosphate in blood: function, metabolism, and fate. Cell Physiol Biochem 2014;34:158-171.

16 Schwalm S, Pfeilschifter J, Huwiler A: Sphingosine-1-phosphate: a Janus-faced mediator of fibrotic diseases. Biochim Biophys Acta 2013;1831:239-250.

17 Yang L, Yue S, Yang L, Liu X, Han Z, Zhang Y, Li L: Sphingosine kinase/sphingosine 1-phosphate (S1P)/S1P receptor axis is involved in liver fibrosis-associated angiogenesis. J Hepatol 2013;59:114-123. 


\section{Cellular Physiology Cell Physiol Biochem 2016;40:1637-1645 \begin{tabular}{ll|l} 
DOI: 10.1159/000453213 & $\begin{array}{l}\text { O 2016 The Author(s). Published by S. Karger AG, Basel } \\
\text { wwww.karger.com/cpb }\end{array}$
\end{tabular}}

Al Fadel et al.: Sphingosine 1-Phosphate and Liver Fibrosis

18 Davaille J, Li L, Mallat A, Lotersztajn S: Sphingosine 1-phosphate triggers both apoptotic and survival signals for human hepatic myofibroblasts. J Biol Chem 2002;277:37323-37330.

19 Donnelly KL, Smith CI, Schwarzenberg SJ, Jessurun J, Boldt MD, Parks EJ: Sources of fatty acids stored in liver and secreted via lipoproteins in patients with nonalcoholic fatty liver disease. J Clin Invest 2005;115:1343-1351.

20 Hetherington AM, Sawyez CG, Zilberman E, Stoianov AM, Robson DL, Borradaile NM: Differential Lipotoxic Effects of Palmitate and Oleate in Activated Human Hepatic Stellate Cells and Epithelial Hepatoma Cells. Cell Physiol Biochem 2016;39:1648-1662.

21 Alvarez SE, Milstien S, Spiegel S: Autocrine and paracrine roles of sphingosine-1-phosphate. Trends Endocrinol Metab 2007;18:300-307.

22 Hu W, Bielawski J, Samad F, Merrill AH, Jr., Cowart LA: Palmitate increases sphingosine-1-phosphate in C2C12 myotubes via upregulation of sphingosine kinase message and activity. J Lipid Res 2009;50:18521862.

23 Japtok L, Schmitz EI, Fayyaz S, Kramer S, Hsu LJ, Kleuser B: Sphingosine 1-phosphate counteracts insulin signaling in pancreatic beta-cells via the sphingosine 1-phosphate receptor subtype 2. FASEB J 2015;29:3357-3369.

24 Takabe K, Kim RH, Allegood JC, Mitra P, Ramachandran S, Nagahashi M, Harikumar KB, Hait NC, Milstien S, Spiegel S: Estradiol induces export of sphingosine 1-phosphate from breast cancer cells via ABCC1 and ABCG2. J Biol Chem 2010;285:10477-10486.

25 Sato M, Ikeda H, Uranbileg B, Kurano M, Saigusa D, Aoki J, Maki H, Kudo H, Hasegawa K, Kokudo N, Yatomi Y: Sphingosine kinase-1, S1P transporter spinster homolog 2 and S1P2 mRNA expressions are increased in liver with advanced fibrosis in human. Sci Rep 2016;6:32119.

26 Ikeda H, Watanabe N, Ishii I, Shimosawa T, Kume Y, Tomiya T, Inoue Y, Nishikawa T, Ohtomo N, Tanoue Y, Iitsuka S, Fujita R, Omata M, Chun J, Yatomi Y: Sphingosine 1-phosphate regulates regeneration and fibrosis after liver injury via sphingosine 1-phosphate receptor 2. J Lipid Res 2009;50:556-564.

27 Li C, Zheng S, You H, Liu X, Lin M, Yang L, Li L: Sphingosine 1-phosphate (S1P)/S1P receptors are involved in human liver fibrosis by action on hepatic myofibroblasts motility. J Hepatol 2011;54:1205-1213.

28 Takuwa N, Ohkura S, Takashima S, Ohtani K, Okamoto Y, Tanaka T, Hirano K, Usui S, Wang F, Du W, Yoshioka K, Banno Y, Sasaki M, Ichi I, Okamura M, Sugimoto N, Mizugishi K, Nakanuma Y, Ishii I, Takamura M, Kaneko S, Kojo S, Satouchi K, Mitumori K, Chun J, Takuwa Y: S1P3-mediated cardiac fibrosis in sphingosine kinase 1 transgenic mice involves reactive oxygen species. Cardiovasc Res 2010;85:484-493. 